\title{
Effects of unilateral and bilateral spreading depression on water intake'
}

ALLEN M. SCHNEIDER

NEW YORK UNIVERSITY

\begin{abstract}
Abstraet
The total amount of water consumed by waterdeprived rats was measured over successive 3-min. intervals of a 30-min. access period before, during and after unilateral or bilateral spreading depression. The results indicated: (a) bilateral spreading depression slowed the rate of drinking and reduced total water intake; (b) unilateral spreading depression slowed the rate of drinking but did not affect total water intake; (c) neither bilateral nor unilateral spreading depression had any aftereffect on the rate of drinking or on total water intake the day following depression.
\end{abstract}

\section{Introduction}

The phenomenon of spreading cortical depression (SD), demonstrated by Leao (1944), consists of a slowly propagating wave ( 2 to $6 \mathrm{~mm}$ per min.) of depressed electrocortical activity. The wave of depressed activity, which can be inititated by electrical, mechanical or chemical stimulation of the cortical surface, propagates over nearly all cortical areas in the stimulated hemisphere but does not spread interhemispherically. Spreading depression initiated by exposure of the cortex to filter paper soaked with $25 \%$ potassium chloride (KC1) solution inactivates cortical activity for 3 to $4 \mathrm{hr}$.

The effects of SD on acquisition and recall processes have been examined using both aversive conditioning (Bures, 1959) and appetitive conditioning (Russell \& Ochs, 1963), but the extent to which SD affects the consummatory aspects of the conditioned response has not been systematically investigated. Recently, Teitelbaum \& Cytawa (1965) reported that bilateral SD abolishes drinking.

To determine the immediate and residual effects of varying degrees of $\mathrm{SD}$ on water consumption, water-deprived Ss were given access to water before, during and after bilateral or unilateral SD. In two yoked control groups, nondepressed water-deprived Ss received, during the treatment days, amounts of water equivalent to those consumed by the depressed Ss. This yoked procedure controlled for the effect of decreased water consumption on the subsequent recovery of water consumption.

\section{Method}

Subjects and Apparatus

Twelve male and 12 female albino rats of the departmental colony, 90-110 days of age and weighing 200$280 \mathrm{gm}$, were deprived of water for $23.5 \mathrm{hr}$. daily and were given free access to Purina lab powder except during the $0.5-\mathrm{hr}$. water-access period. Water consumption, monitored at $3-\mathrm{min}$. intervals during the $0.5-\mathrm{hr}$. water-access period, was measured with a 100-ml Richter drinking tube calibrated in 1-ml units.

\section{Procedure}

The 24 Ss were assigned to four groups of six Ss each, matched on the basis of water intake. The Ss in the experimental groups were given access to water $40 \mathrm{~min}$. prior to the controls, and the $12 \mathrm{Ss}$ in each group (experimental and control) were tested simultaneously. This procedure of running the experimental Ss prior to the controls made it possible, in a later stage of the procedure, to adjust the treatment received by the control Ss according to the performance of their corresponding experimental Ss.

Ss were surgically prepared for SD following the water-access period on day 14 , and were given four days of postoperative recovery. The surgical preparation is described in detail elsewhere (Schneider \& Behar, 1964).

On day 19 the treatment was administered to the four groups. Spreading depression was elicited by exposing the cortex to a small cotton pledget soaked with $25 \%$ KC1 solution. The two experimental groups were subjected to SD $10 \mathrm{~min}$. prior to the water-access period; group USD (unilateral SD) received SD in one hemisphere, whereas group BSD (bilateral SD) received SD in both hemispheres. Half the Ss receiving USD received $\mathrm{SD}$ in the right and half in the left hemisphere. The data for these subgroups were combined since there were no differences in their water intake. The two control groups, UC (unilateral control) and $\mathrm{BC}$ (bilateral control), were not subjected to SD during the water-access period on day 19. Rather, each control $\mathrm{S}$ was given access to an amount of water equal to that consumed by its corresponding experimental S. The amount of water given each control $\mathrm{S}$ on the treatment days was determined by matching its percentage of normal water intake (estimated by the mean amount of water consumed during the two days prior to SD) with the percentage of normal intake consumed by its corresponding depressed $\mathrm{S}$ on the treatment day. After four days of recovery, the treatment-recovery procedure was repeated.

Fvaluation of Results

The statistical evaluation of the results was based on a trend analysis of variance for matched groups (Edwards, 1960); the two treatment-recovery cycles (Test 1 and Test 2) were analyzed separately. 


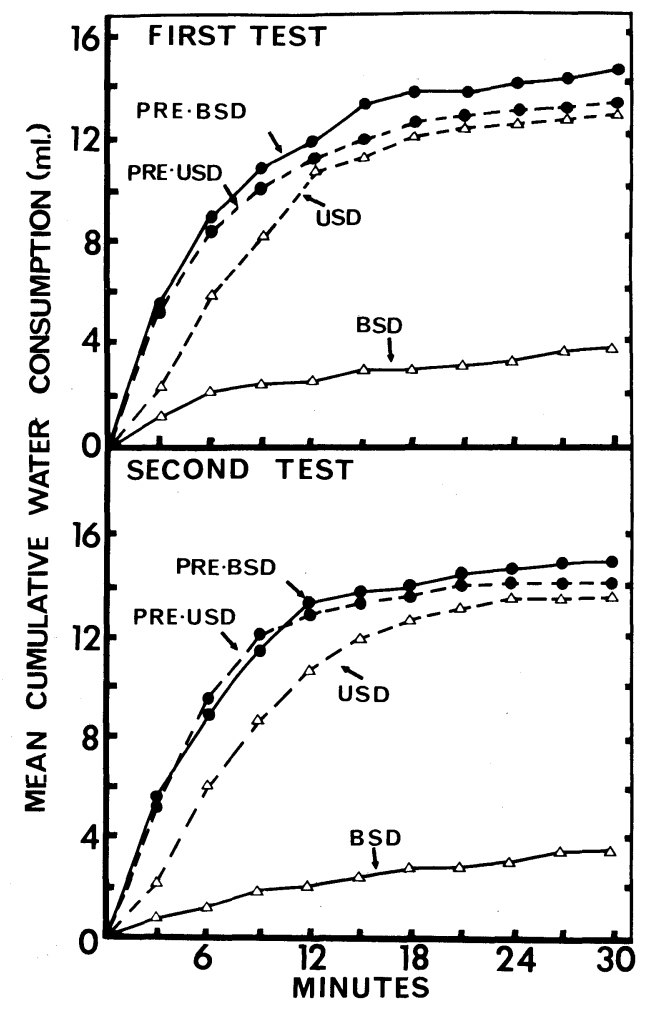

Fig 1. The mean cumulative amount of water consumed by the USD and BSD groups in successive 3-min intervals on the pretreatment (Pre-BSD, Pre-USD) and treatment days (BSD, USD). Days 18 and 19 are represented in the first test: days 23 and 24 are represented in the second test.

\section{Results}

Figure 1 presents the water intake for the depressed groups before (Pre-BSD and Pre-USD) and during (BSD and USD) depression. Both USD and BSD produced a decrease in water intake. During the pre-treatment days most of the drinking occurred early in the session and amounted to approximately $14 \mathrm{ml}$ over the $30-\mathrm{min}$. access period. On the other hand, during the treatment days BSD produced a sustained decrement in the intake throughout the $30-\mathrm{min}$. period, resulting in a total intake of approximately $4 \mathrm{ml}$; USD produced an initial, decrement in the rate of intake but did not affect the total intake, which reached the pre-treatment level of approximately $14 \mathrm{ml}$.

Analysis of variance showed that BSD and USD produced a significant decrease in rate of drinking during each test; all day $x$ interval interactions achieved significance at the .01 level except that for USD on days 18 and 19 which achieved significance at the .05 level. In the analysis of total water intake, the two Fs for $\mathrm{BSD}$, comparing total intake on day 18 with day 19 and total intake on day 23 with day 24 , were significant beyond the .01 level; the same comparisons for USD yielded Fs less than unity.
Two results indicate that $\mathrm{SD}$ has no aftereffect on water intake. First, the control Ss dic no differ , ori the experimental Ss in the total amount of water consumed nor in the rate of drinking during the post-treatment days ( $p$ 's $>.05$ ); second, within each group, the amount of water consumed and the rate of drinking during the pre-treatment days did not differ from the post-treatment days ( $p$ 's $>.05$ ). It is interesting to note that the marked decrease in water intake in the BSD and BC groups during the treatment days, leaving most Ss in the two groups $47.5 \mathrm{hr}$. deprived on the first post-treatment day, did not produce a compensatory increase in water intake above the pretreatment level.

\section{Discussion}

The present experiment verified the adipsic effect of BSD reported by Teitelbaum \& Cytawa (1965) and showed that USD affected the rate of drinking but not the total water intake. The selective effect of USD on the rate of drinking independent of the total intake suggests that motor factors governing the licking response may be impaired to different degrees by USD and BSD, slowing the rate in the former case and abolishing the response in the latter case. The implication of motor impairment is further substantiated by observations in the present experiment that Ss under BSD frequently spent the initial part of their access period in the vicinity of the water tube, gnawing at its edges as if motivated but physically incapable of drinking.

The effect of SD on water intake indicates that decrements in performance, previously attributed to impaired conditioning or retention processes (Bures, 1959), may reflect, at least in part, a motor decrement. This conclusion is similar to one proposed by Tapp (1962), who found that under BSD, Ss impaired in avoidance conditioning were frequently impaired in a test for motor coordination.

\section{References}

Bures, J. Functional decortication and behavior. In M. A. B Brazier (Ed,), Conjerence on the central nervous system and behavior. New York: Josiah Macey, Jr., Foundation, 1959.

Edwards, A. L. Experimental design in psychological research. (Rev: ed.) New York: Rinehart and Co., 1960.

Leao; A. A. P. Spreading depression of activity in the cerebral cortex. J. Neurophysiol., 1944, 7, 359-390.

Russell. I. S., \& Ochs, S. One trial interhemispheric transfer of a learning engram. Science, 1961, 13, 1077-1078.

Schneider, A. M, \& Behar, M. A chronic preparation for spreading cortical depression. J. exp. Anal. Behav., 1964, 7, 350

Tapp, J. T. Reversible cortical depression and avoidance behavior in the rat. J. comp. physiol. Psychol., 1962, 55, 306-308.

Teitelbaum, P. \& Cytawa, J. Spreading depression and recovery from lateral hypothalamic damage. Science, 1965, 147, 61-63.

\section{Note}

1. This study was supported by NIMH Grant, MH 10667-01. The author is grateful to A C Catania for his critical reading of the manuscript and to Neil Martin and Steven King for their valuable assistance in the collection of data. 